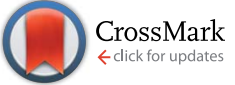

Cite this: RSC Adv., 2017, 7, 12359

\title{
Spectroscopic and thermodynamic investigations of clathrate hydrates of methacrolein
}

\author{
Yun-Ho Ahn, ${ }^{a}$ Yeobum Youn, ${ }^{a}$ Minjun $C h a{ }^{* b}$ and Huen Lee ${ }^{\star a}$
}

This study characterized new structure II (sIl) clathrate hydrates, consisting of $136 \mathrm{H}_{2} \mathrm{O}$ molecules with 8 large $5^{12} 6^{4}$ cages and 16 small $5^{12}$ cages, with methacrolein for the first time. The crystal structure and guest distributions of binary (methacrolein + gaseous guests) clathrate hydrates were identified using spectroscopic tools, namely powder X-ray diffraction (PXRD) and Raman spectroscopy. The PXRD and Raman results showed that the inclusion of methacrolein and gaseous guests including $\mathrm{CH}_{4}, \mathrm{~N}_{2}, \mathrm{O}_{2}$ or $\mathrm{CO}_{2}$ could be monitored in the large and small cages of sll hydrates, respectively. The conformation of methacrolein in the large cages of sll hydrates was also analyzed via Raman spectroscopy, revealing an s-trans conformer of methacrolein in the large cages of sll hydrates. High-resolution powder diffraction (HRPD) and Raman spectroscopy were also used to identify the dissociation of binary (methacrolein + $\mathrm{CH}_{4}$ ) clathrate hydrate, showing that it was almost completely dissociated at $200 \mathrm{~K}$. Finally, we measured the equilibrium conditions of four phases, clathrate hydrates, liquid water, liquid methacrolein, and the vapour phase, to check the thermodynamic stability of binary (methacrolein + gaseous guest) clathrate hydrates. The phase equilibria of binary (methacrolein $+\mathrm{CH}_{4}, \mathrm{~N}_{2}$, or $\mathrm{O}_{2}$ ) clathrate hydrates showed that the addition of methacrolein to the hydrate phase increased the hydrate stability with a higher hydrate dissociation temperature when compared to the hydrate stability of pure $\left(\mathrm{CH}_{4}, \mathrm{~N}_{2}\right.$, or $\left.\mathrm{O}_{2}\right)$ clathrate hydrates. The thermodynamic stability of binary (methacrolein $+\mathrm{CO}_{2}$ ) clathrate hydrate exhibits a higher hydrate dissociation temperature when compared with that of the pure $\mathrm{CO}_{2}$ clathrate hydrate below $279 \mathrm{~K}$.

Received 20th December 2016 Accepted 10th February 2017

DOI: 10.1039/c6ra28434e

rsc.li/rsc-advances hydrates can be formed at low temperature and high pressure conditions, and so the focus has shifted onto finding ways to promote their formation under thermodynamic conditions. The injection of large organic guest molecules into clathrate hydrate systems is the key technology for promoting hydrate equilibrium conditions. For determining the thermodynamic conditions of clathrate hydrates, the chemical and physical properties of large organic guest molecules are recognized as key factors. ${ }^{5-7}$ Hence, many large guest molecules (LGMs) have been extensively investigated as hydrate formers in the presence of a help gas..$^{-20}$

Recent studies have reported an interesting phenomenon for the inclusion of large guest molecules (LGMs) in the large cages of sII or sH hydrates..$^{8-20}$ It was reported that the trans conformation of some large guest molecules (LGMs), such as $n$-butane and isopentane, is thermodynamically preferred in the neat phase, but the gauche conformation of LGMs is observed in the large cages of sII or sH hydrates. ${ }^{8-11,15}$ In addition, it was recently reported that some alcohols with molecular sizes above $7.5 \AA$ form sII hydrates in the presence of methane gas. ${ }^{13,19} 1$-Butanol with a molecular size of $9.05 \AA$ and a trans-trans conformation may not be considered as an sII hydrate former from the viewpoint of guest inclusion, but 1-butanol with a molecular size of $7.72 \AA$ and a gauche-gauche conformation is reported to be an sII hydrate former in the presence of methane gas. ${ }^{13,19}$ Ahn et al.

\footnotetext{
${ }^{a}$ Department of Chemical and Biomolecular Engineering (BK21+ Program), Korea Advanced Institute of Science and Technology (KAIST), 291 Daehak-ro, Yuseong-gu, Daejeon 305-701, Republic of Korea. E-mail: hlee@kaist.ac.kr

${ }^{b}$ Department of Energy and Resources Engineering, Kangwon National University, 1 Kangwondaehak-gil, Chuncheon-si, Gangwon-do 200-701, Republic of Korea. E-mail: minjun.cha@kangwon.ac.kr
}

that are composed of hydrogen-bonded 'host' water frameworks and encapsulated small 'guest' molecules, such as methar crystal structure of common clathrate hydrates can be classified into three general types: cubic structure I (sI), consisting of 46 $\mathrm{H}_{2} \mathrm{O}$ molecules with 6 large $5^{12} 6^{2}$ cages and 2 small $5^{12}$ cages, cubic structure II (sII), consisting of $136 \mathrm{H}_{2} \mathrm{O}$ molecules with 8 large $5^{12} 6^{4}$ cages and 16 small $5^{12}$ cages, and hexagonal structure $\mathrm{H}(\mathrm{sH})$, consisting of $34 \mathrm{H}_{2} \mathrm{O}$ molecules with 1 large $5^{12} 6^{8}$

The $5^{12}$ (small) cage is the basic building-block for common hydrate structures, and several kinds of small gaseous molehydrates have received much attention in the energy and environmental fields for gas storage and transportation., ${ }^{3,4}$ Clathrate 
also investigated the inclusion of 3-butene-2-one as an sII hydrate former in the presence of methane gas and its preferred conformation in the large cages of sII hydrates. ${ }^{20}$ Similar to the gauche conformation of $n$-butane in the large cages of sII hydrates, the s-cis conformation of 3-butene-2-one is preferred in hydrate cages. ${ }^{\mathbf{8 - 1 1 , 1 5 , 2 0}}$ Information on the inclusion of guest molecules and the conformation of LGMs in hydrate cages might be useful to better understand the nature of a host-guest system. Therefore, it should be useful to investigate whether the inclusion of methacrolein (also called 2-methylpropenal) can form an SII or sH clathrate hydrate or not in the presence of gaseous guest molecules such as $\mathrm{CH}_{4}, \mathrm{~N}_{2}, \mathrm{O}_{2}$ or $\mathrm{CO}_{2}$, and what types of methacrolein conformers are possible in the large cages of sII or sH hydrates.

In this study, methacrolein is introduced as a new hydrate former in the presence of gaseous guest molecules for the first time. We reveal the crystal structure and guest distributions of binary (methacrolein + gaseous guests, such as $\mathrm{CH}_{4}, \mathrm{~N}_{2}, \mathrm{O}_{2}$ or $\mathrm{CO}_{2}$ ) clathrate hydrates using spectroscopic tools, specifically powder X-ray diffraction (PXRD) and Raman spectroscopy. Finally, we measure the equilibrium conditions of four phases, clathrate hydrates $(\mathrm{H})$, liquid water $\left(\mathrm{L}_{\mathrm{W}}\right)$, liquid methacrolein ( $\left.\mathrm{L}_{\text {methacrolein }}\right)$, and vapour $(\mathrm{V})$, to check the thermodynamic stability of binary (methacrolein + gaseous guest) clathrate hydrates. ${ }^{21}$

\section{Experimental section}

\section{Materials and sample preparation}

Methacrolein (2-methylpropenal, 95 mol\% purity) was purchased from Sigma Aldrich Inc. Methane $\left(\mathrm{CH}_{4}\right)$, oxygen $\left(\mathrm{O}_{2}\right)$, nitrogen $\left(\mathrm{N}_{2}\right)$, and carbon dioxide $\left(\mathrm{CO}_{2}\right)$ gases were supplied by Special Gas (Republic of Korea) with stated minimum purities of 99.95, 99.95, 99.9, and 99.9 mol\%, respectively. Deionized water was supplied from a Millipore purification unit. The liquid methacrolein solutions (5 mol\%, slightly less concentrated than the stoichiometric amount for the large cages of structure II hydrates) were loaded into high pressure resistant reactors (inner volume of $200 \mathrm{ml}$ with a vertical magnetic drive agitator). Here, $5 \mathrm{~mol} \%$ of methacrolein solution is used to minimize the number of unreacted methacrolein molecules. The reactors were placed in a circulating water bath (Jeio Tech., RW-2040G model) at $288 \mathrm{~K}$, and pressurized with methane $\left(\mathrm{CH}_{4}\right)$, oxygen $\left(\mathrm{O}_{2}\right)$, nitrogen $\left(\mathrm{N}_{2}\right)$, or carbon dioxide $\left(\mathrm{CO}_{2}\right)$ gas up to the desired pressure conditions. The pre-existing air in the reactor was flushed out with a continuous injection of the desired gas before pressurization using a microflow syringe pump (Teledyne, ISCO 100D). The temperature of the system decreased to $274 \mathrm{~K}$ at a cooling rate of $0.5 \mathrm{~K} \mathrm{~h}^{-1}$. The hydrate formation was monitored via a sudden pressure drop. The degree of hydrate conversion was checked by monitoring the continuous pressure drop, and we assumed that the hydrate conversion was complete after reaching pressure stabilization. The binary hydrate samples were then ground under liquid nitrogen with a $100 \mu \mathrm{m}$ sieve. The powdered hydrate samples were used for spectroscopic analysis.

\section{Powder X-ray diffraction (PXRD) and high-resolution powder} diffraction (HRPD) patterns

The powder X-ray diffraction (PXRD) patterns of binary (methacrolein $+\mathrm{CH}_{4}, \mathrm{~N}_{2}, \mathrm{O}_{2}$, and $\mathrm{CO}_{2}$ ) clathrate hydrates were measured using a Rigaku D/Max-2500 model diffractometer with $\mathrm{CuK} \alpha$ as the light source (with a wavelength of $1.5406 \AA$ ) at a generator voltage of $40 \mathrm{kV}$ and a generator current of $300 \mathrm{~mA}$. The $\theta / 2 \theta$ mode with $3 \mathrm{~s}$ for the fixed time and $0.02^{\circ}$ for the step size from $2 \theta=5-55^{\circ}$ was used for the PXRD measurements. A low-temperature stage attached to the PXRD unit maintained the working temperature at $93 \mathrm{~K}$ using liquid nitrogen to minimize possible sample damage. The High-Resolution Powder Diffraction (HRPD) patterns of the binary (methacrolein $+\mathrm{CH}_{4}$ ) clathrate hydrate were also measured using the High-Resolution Powder Diffraction Beamline (9B) at Pohang Accelerator Laboratory (PAL). During the measurements, the $\theta /$ $2 \theta$ mode with $2 \mathrm{~s}$ for the fixed time and $0.01^{\circ}$ for the step size from $2 \theta=5-125^{\circ}$ was used for the HRPD measurements. A beamline with a wavelength of $1.5472 \AA$ was used. The HRPD patterns were obtained at various temperatures (93, 153, and $203 \mathrm{~K})$ using liquid nitrogen to characterize the temperaturedependent hydrate dissociation behavior of the binary (methacrolein $+\mathrm{CH}_{4}$ ) clathrate hydrate.

\section{Raman spectroscopy}

A dispersive Raman spectrometer (Horiba Jobin Yvon ARAMIS) with a CCD (Charge-Coupled Device) detector and electrical cooling $(203 \mathrm{~K})$ was used to monitor the guest inclusion behaviors and conformation of methacrolein in the hydrate cages. The excitation source was an Ar-ion laser emitting a $514.53 \mathrm{~nm}$ beam. The intensity of the laser was typically 30 $\mathrm{mW}$. The system temperature was controlled using a Linkam temperature controller (THMS600G model). For temperaturedependent Raman measurements, the sample temperature of the microscope stage was varied from 93 to $213 \mathrm{~K}$.

\section{Phase equilibrium measurements}

Four phase $\left(\mathrm{H}+\mathrm{L}_{\mathrm{W}}+\mathrm{L}_{\text {methacrolein }}+\mathrm{V}\right)$ equilibria of the binary (methacrolein $+\mathrm{CH}_{4}, \mathrm{~N}_{2}, \mathrm{O}_{2}$ or $\mathrm{CO}_{2}$ ) clathrate hydrates were measured using a high pressure resistance reactor (with an inner volume of $200 \mathrm{ml}$ ). First, a reactor with a four-wire Pt-100 $\Omega$ thermometer probe, a resolution of $0.01 \mathrm{~K}$ and a pressure transducer (Druck, PMP5073) with an accuracy of $0.02 \%$ was charged with the methacrolein aqueous solution. After loading the solution, the reactor was pressurized with $\mathrm{CH}_{4}, \mathrm{~N}_{2}, \mathrm{O}_{2}$, or $\mathrm{CO}_{2}$ gas until the desired pressure was reached. After the system stabilization process, the hydrate formation was initiated by cooling the circulating bath at a cooling rate of $1 \mathrm{~K} \mathrm{~h}^{-1}$. After the hydrate formation step, the temperature of the circulating bath was slowly increased in a step-wise manner at $0.1 \mathrm{~K} \mathrm{~h}^{-1}$ to supply sufficient equilibrium time. The equilibrium conditions of binary (methacrolein $+\mathrm{CH}_{4}, \mathrm{~N}_{2}, \mathrm{O}_{2}$, or $\mathrm{CO}_{2}$ ) clathrate hydrates can be obtained from the sharp intersection point of the cooling and heating curves in the temperature and pressure traces. The temperature and pressure changes during the 
hydrate formation and dissociation processes were automatically recorded using a data acquisition system.

\section{Results and discussion}

Three well-known classes of clathrate hydrate structures, structure I (sI, space group: cubic $P m \overline{3} n$ ), structure II (sII, space group: cubic $F d \overline{3} m$ ), and structure $\mathrm{H}$ (sH, space group: hexagonal $P 6 / \mathrm{mmm}$ ), are categorized according to the differences in the type of crystal system, and the size and shape of the hydrate cages. ${ }^{1,2}$ Due to the upper size limits of the hydrate cages, guest molecules of a suitable size can be enclathrated into the hydrate cages, leading to the selective enclathration of guest molecules. ${ }^{1,2}$ Therefore, large guest molecules (LGMs) with a molecular size above $7.5 \AA$ are considered to be enclathrated into the large $\left(5^{12} 6^{8}\right)$ cages of an $\mathrm{sH}$ hydrate..$^{1,2,13,19}$ To determine the molecular size of methacrolein, the equilibrium molecular structures of methacrolein were calculated using the Gaussian 03 program $^{22}$ with the B3LYP model and the $6-311++\mathrm{G}(\mathrm{d}, \mathrm{p})$ basis set (Fig. 1). Two asymmetric groups, including $\mathrm{CH}_{2}=$ $\mathrm{C}\left(\mathrm{CH}_{3}\right)$ and $\mathrm{CHO}$, are connected by a single covalent bond, and thus two stable conformers, denoted as s-cis and s-trans (Fig. 1), can be constructed by the rotation of a single covalent bond, resulting in all of the heavy atoms being located in the same plane ${ }^{23-25}$ Fig. 1 clearly shows the equilibrium structures and molecular size of the s-cis $(7.24 \AA)$ and s-trans $(7.19 \AA)$ methacrolein conformers. Therefore, the formation of sII or $\mathrm{sH}$ hydrates in the presence of help gases, such as $\mathrm{CH}_{4}, \mathrm{~N}_{2}, \mathrm{O}_{2}$, or $\mathrm{CO}_{2}$, is possible at low temperature and high pressure conditions.

In order to identify the crystal structures and guest inclusion behaviors of binary (methacrolein + gaseous guests) clathrate hydrates, powder X-ray diffraction (PXRD) and Raman spectroscopy measurements were performed at $93 \mathrm{~K}$. Fig. 2 shows the PXRD patterns of binary (methacrolein + gaseous guests) clathrate hydrates, where methane $\left(\mathrm{CH}_{4}\right)$, nitrogen $\left(\mathrm{N}_{2}\right)$, oxygen $\left(\mathrm{O}_{2}\right)$, or carbon dioxide $\left(\mathrm{CO}_{2}\right)$ were used as help gases. The crystal structures of the clathrate hydrate samples were analyzed and identified as the cubic $F d \overline{3} m$ structure with a lattice constant of $a=17.328(16) \AA$ for $\mathrm{CH}_{4}, a=17.236(17) \AA$ for $\mathrm{N}_{2}, a=17.260(19) \AA$ for $\mathrm{O}_{2}$, and $a=17.310(34) \AA$ for

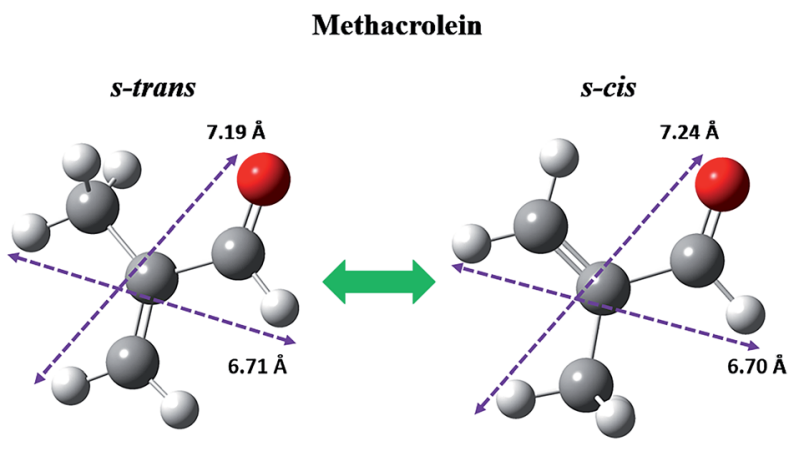

Fig. 1 Conformational isomers of methacrolein and their van der Waals molecular sizes. Gray, white, and red balls represent carbon, hydrogen, and oxygen, respectively.

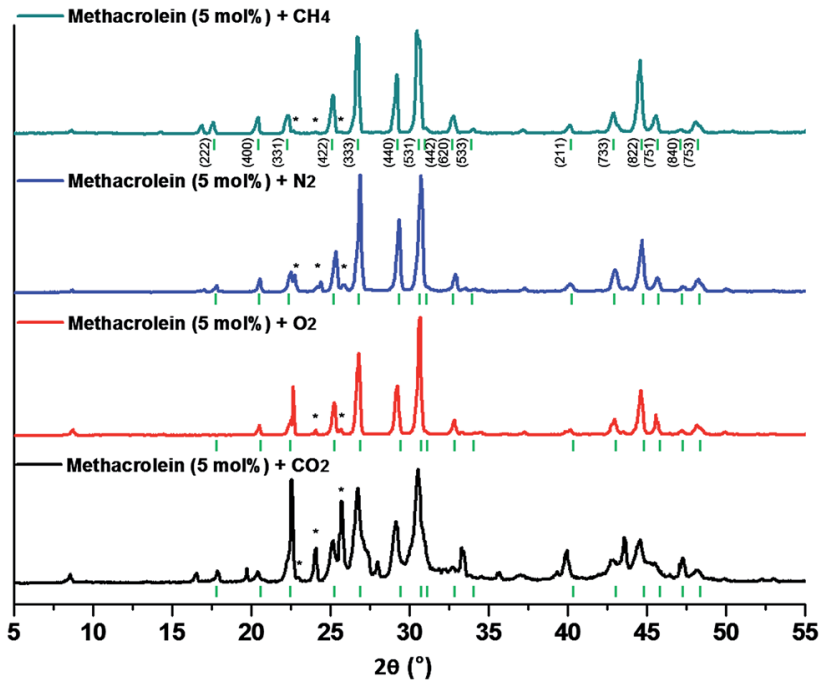

Fig. 2 PXRD patterns of the binary methacrolein $(5 \mathrm{~mol} \%)+\mathrm{CH}_{4}$ (dark cyan), $\mathrm{N}_{2}$ (blue), $\mathrm{O}_{2}$ (red), and $\mathrm{CO}_{2}$ (black) hydrates.

$\mathrm{CO}_{2}{ }^{1,2,13,19}$ The lattice constant for the cubic $F d \overline{3} m$ structure is close to the value reported in the literature, ${ }^{1,2}$ and the bars below the PXRD patterns indicate the diffraction peaks from the cubic $F d \overline{3} m$ structure. As for the impurities, a hexagonal ice phase from unreacted water can be observed in the PXRD patterns, as indicated by an asterisk (*) in Fig. 2. Due to the molecular size of methacrolein (Fig. 1), it might be suitable to be enclathrated into only the large $5^{12} 6^{4}$ cages of sII clathrate hydrates.

Fig. 3 shows spectra from the inclusion of the gaseous guest molecules, methane $\left(\mathrm{CH}_{4}\right)$, nitrogen $\left(\mathrm{N}_{2}\right)$, oxygen $\left(\mathrm{O}_{2}\right)$, and carbon dioxide $\left(\mathrm{CO}_{2}\right)$, in the cages of sII clathrate hydrates. For the binary (methacrolein $+\mathrm{CH}_{4}$ ) clathrate hydrate shown in dark cyan (Fig. 3), the enclathrated $\mathrm{CH}_{4}$ molecules in the small $5^{12}$ cages of sII clathrate hydrates can be identified using the C-H vibrational region of the Raman spectra at around 2914 $\mathrm{cm}^{-1} \cdot{ }^{2,13,19}$ Because $5 \mathrm{~mol} \%$ (slightly less concentrated than the stoichiometric amount for the large cages of structure II hydrates) of methacrolein solution was used to minimize the number of unreacted methacrolein molecules, the relatively weak Raman signal at around $2904 \mathrm{~cm}^{-1}$ indicates a small amount of the $\mathrm{CH}_{4}$ molecules in the large cages of the sII clathrate hydrate. ${ }^{2}$ Similarly, the representative Raman signals for $\mathrm{N}_{2}$ or $\mathrm{O}_{2}$ in the sII hydrates were observed at around 2322 $\mathrm{cm}^{-1}$ for the $\mathrm{N}-\mathrm{N}$ symmetric stretching mode of $\mathrm{N}_{2}$ (blue line in Fig. 3) and $1546 \mathrm{~cm}^{-1}$ for the $\mathrm{O}-\mathrm{O}$ symmetric stretching mode of $\mathrm{O}_{2}$ (red line in Fig. 3). Moreover, the representative Raman signals for $\mathrm{CO}_{2}$ in the small cages of sII hydrates (black line in Fig. 3) were also observed at around 1274 and $1380 \mathrm{~cm}^{-1}$ for the vibrational frequencies of $\mathrm{CO}_{2} \cdot{ }^{26}$ Chen et al. investigated the vibrational frequencies of $\mathrm{CO}_{2}$ in the small and large cages of sI or sII hydrates, and their findings are in good agreement with our results. ${ }^{26}$

At this stage, the identification of gaseous guest molecules in the small cages of sII hydrates has been successfully demonstrated, but the types of methacrolein conformers in the large 


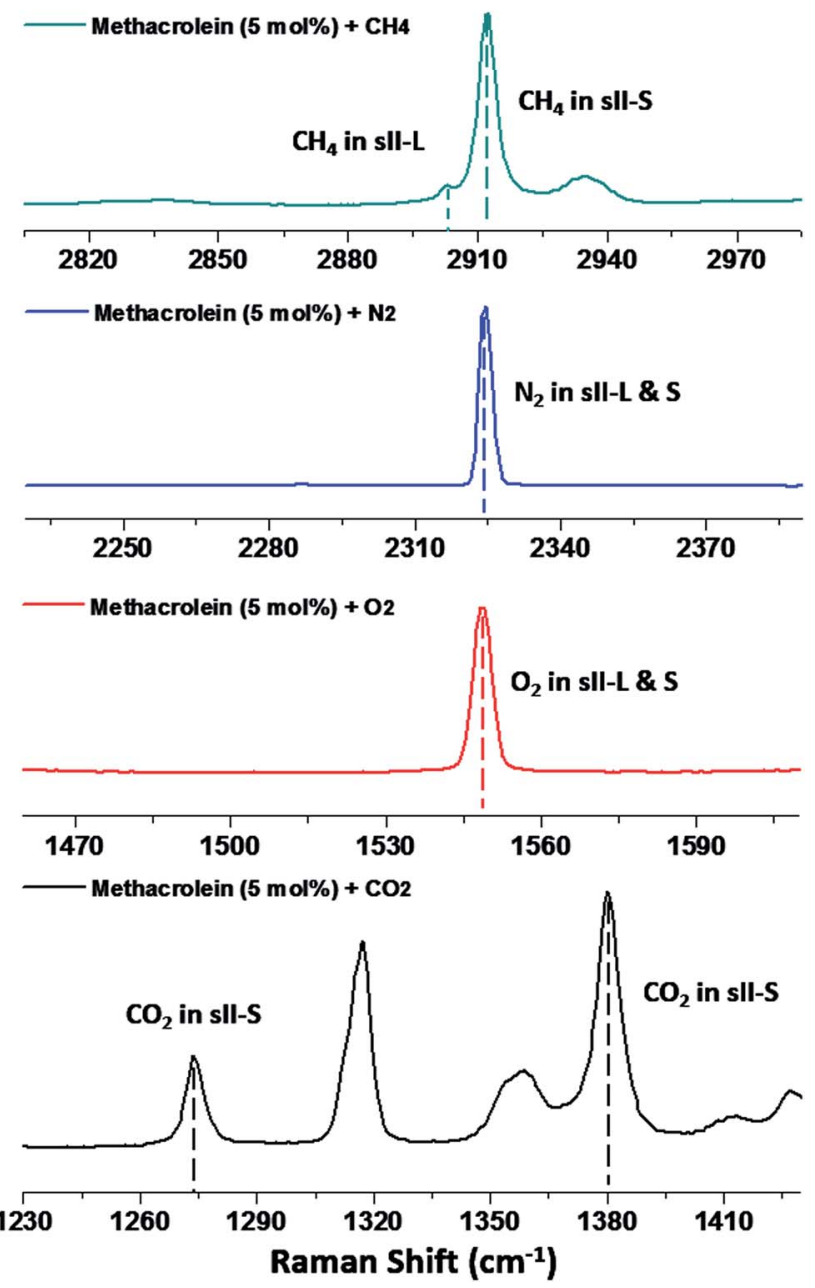

Fig. 3 Raman spectra of the binary clathrate hydrates composed of methacrolein (5 mol\%) $+\mathrm{CH}_{4}$ (dark cyan), $\mathrm{N}_{2}$ (blue), $\mathrm{O}_{2}$ (red), and $\mathrm{CO}_{2}$ (black).

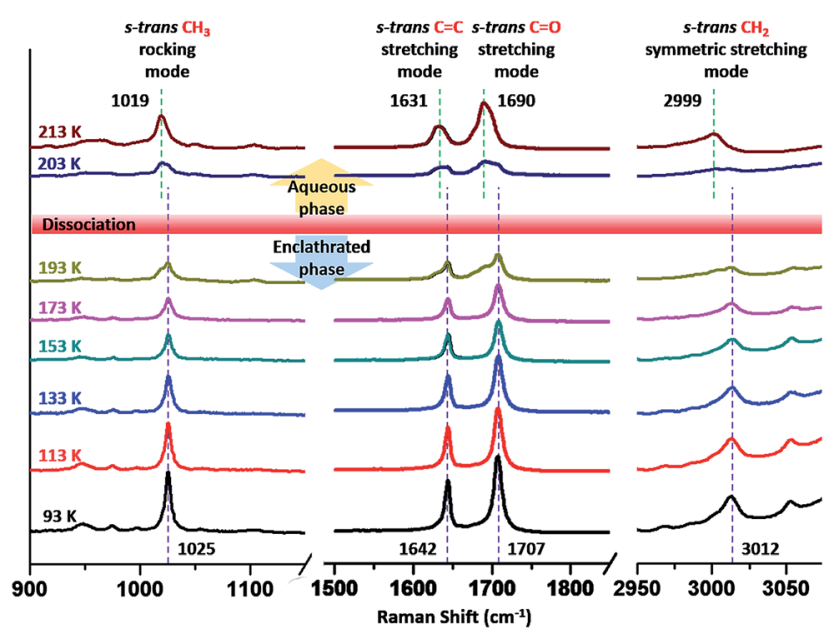

Fig. 4 Raman spectra of binary methacrolein $(5 \mathrm{~mol} \%)+\mathrm{CH}_{4}$ hydrate measured at various temperatures. cages of sII hydrates remain unknown. In Fig. 4, the Raman spectra of the binary (methacrolein $+\mathrm{CH}_{4}$ ) clathrate hydrate are shown with various temperature conditions in the range of 93 to $213 \mathrm{~K}$. The $\mathrm{CH}_{3}$ rocking mode (around $1000 \mathrm{~cm}^{-1}$ ), $\mathrm{C}=\mathrm{C}$ and $\mathrm{C}=\mathrm{O}$ stretching modes $\left(1600-1700 \mathrm{~cm}^{-1}\right)$, and $=\mathrm{CH}_{2}$ symmetric stretching mode (around $3000 \mathrm{~cm}^{-1}$ ) of methacrolein can be observed at various temperature conditions, as shown in Fig. $4 .^{23}$ To clearly identify the conformational information for methacrolein, we focused on the $=\mathrm{CH}_{2}$ symmetric stretching mode of methacrolein in the Raman spectra. At $93 \mathrm{~K}$, the enclathration of methacrolein in the large cages of the sII clathrate hydrate is revealed by the strong Raman signal at around $3012 \mathrm{~cm}^{-1}$. Durig et al. ${ }^{23}$ investigated the Raman spectra of s-cis and s-trans methacrolein in the solid, liquid, and gas phases, and the strong Raman peaks at around $3007 \mathrm{~cm}^{-1}$ and $2993 \mathrm{~cm}^{-1}$ were assigned to s-trans and s-cis methacrolein, respectively, in the gas phase. In Fig. 4, a Raman signal occurring at $3012 \mathrm{~cm}^{-1}$ at temperatures below $193 \mathrm{~K}$ disappeared as the temperature rose, and a new Raman signal occurring at $2999 \mathrm{~cm}^{-1}$ appeared at temperatures above $193 \mathrm{~K}$. Considering the previous Raman assignment of methacrolein in the neat phase ${ }^{23}$ it is reasonable to conclude that s-trans methacrolein is enclathrated in the large cages of sII hydrates, and the s-trans methacrolein in the aqueous phase $\left(2999 \mathrm{~cm}^{-1}\right)$ appears with the dissociation of the hydrate. Ahn et al. reported that the preferred conformer of 3-butene-2-one in the large cages of sII clathrate hydrates is the s-cis conformer, and we revealed that the preferred conformation of methacrolein in the large cages of sII clathrate hydrates might be the s-trans conformer. ${ }^{20}$ The relative energy of s-cis methacrolein with respect to that of strans methacrolein was calculated to explain the reason for the enclathration of s-trans methacrolein in the large cages of sII hydrates, and the relative energy difference was calculated as 14 $\mathrm{kJ} \mathrm{mol}^{-1}$, implying that the s-cis conformer of methacrolein is unfavorable for enclathration in hydrate cages. In addition, the rotation barrier between the two stable conformers, s-cis and strans (Fig. 1), was identified by Zakharenko et al. and it was reported to be about $34 \mathrm{~kJ} \mathrm{~mol}^{-1} .^{25}$ Therefore, the enclathration of s-cis methacrolein in the large cages of sII hydrates may be

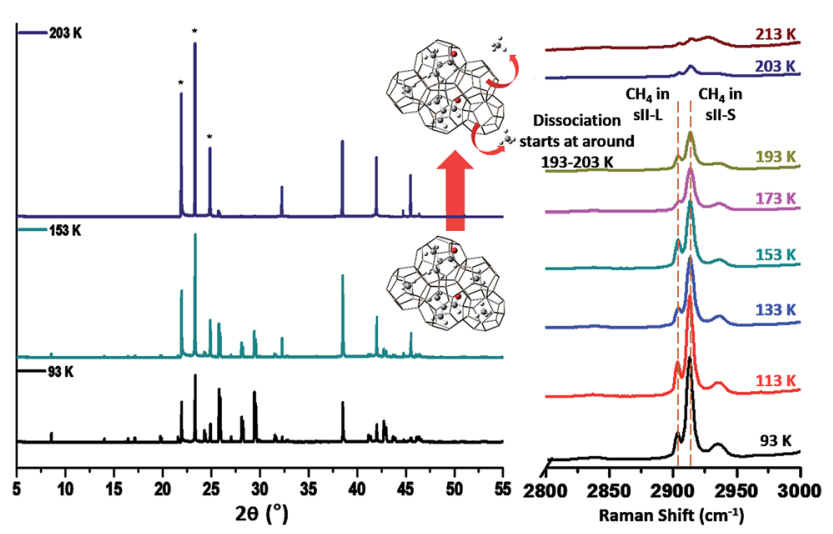

Fig. 5 Synchrotron HRPD patterns and Raman spectra of binary methacrolein $(5 \mathrm{~mol} \%)+\mathrm{CH}_{4}$ hydrate recorded at various temperatures. 
impossible due to its high relative energy and the rotation barrier.

The Raman spectra of the $\mathrm{CH}_{3}$ rocking mode of methacrolein exhibit a similar trend to the $\mathrm{CH}_{2}$ symmetric stretching mode. At $93 \mathrm{~K}$, the sole Raman signal, located at $1025 \mathrm{~cm}^{-1}$, which can be identified as the $\mathrm{CH}_{3}$ rocking mode in s-trans methacrolein in the large cages of the sII hydrate, disappeared at around $203 \mathrm{~K}$ and a new Raman signal at $1019 \mathrm{~cm}^{-1}$ clearly appeared after the complete dissociation of the hydrate at around $213 \mathrm{~K}$, indicating s-trans methacrolein in the aqueous phase. Similarly, we observed the $\mathrm{C}=\mathrm{C}$ and $\mathrm{C}=\mathrm{O}$ stretching modes of enclathrated s-trans methacrolein below $203 \mathrm{~K}$ (1642 $\mathrm{cm}^{-1}$ and $1707 \mathrm{~cm}^{-1}$, respectively) and the same modes of aqueous s-trans methacrolein above $203 \mathrm{~K}\left(1631 \mathrm{~cm}^{-1}\right.$ and 1690 $\mathrm{cm}^{-1}$, repsectively). ${ }^{23}$

The dissociation behaviors of the binary (methacrolein + $\mathrm{CH}_{4}$ ) clathrate hydrate were analyzed using Raman spectra of the $\mathrm{C}-\mathrm{H}$ vibrational mode of $\mathrm{CH}_{4}$ and high-resolution powder diffraction (HRPD) patterns, as shown in Fig. 5. From $93 \mathrm{~K}$ to $153 \mathrm{~K}$, there was no significant change in the relative intensity of the $\mathrm{CH}_{4}$ molecules in both small and large cages of the sII hydrate. However, the relative intensity of the $\mathrm{CH}_{4}$ molecules gradually decreased from 153 to $193 \mathrm{~K}$. The binary (methacrolein $+\mathrm{CH}_{4}$ ) clathrate hydrate then started to dissociate rapidly at around 193-203 $\mathrm{K}$. The dissociation behaviors of the binary (methacrolein $+\mathrm{CH}_{4}$ ) clathrate hydrate were also monitored using the temperature-dependent HRPD patterns, as shown in Fig. 5, and the binary (methacrolein $+\mathrm{CH}_{4}$ ) clathrate hydrate was almost completely dissociated at around $203 \mathrm{~K}$.

Finally, we measured the equilibrium conditions of four phases, clathrate hydrates $(\mathrm{H})$, liquid water $\left(\mathrm{L}_{\mathrm{W}}\right)$, liquid methacrolein $\left(\mathrm{L}_{\text {methacrolein }}\right)$, and vapour $(\mathrm{V})$, to check the thermodynamic stability of the binary (methacrolein + gaseous guest) clathrate hydrates using the conventional isochoric method. ${ }^{21}$ The equilibrium conditions of the binary (methacrolein + gaseous guest molecules) hydrates were measured at pressures ranging from 2 to $15 \mathrm{MPa}$ and temperatures ranging from 284 to

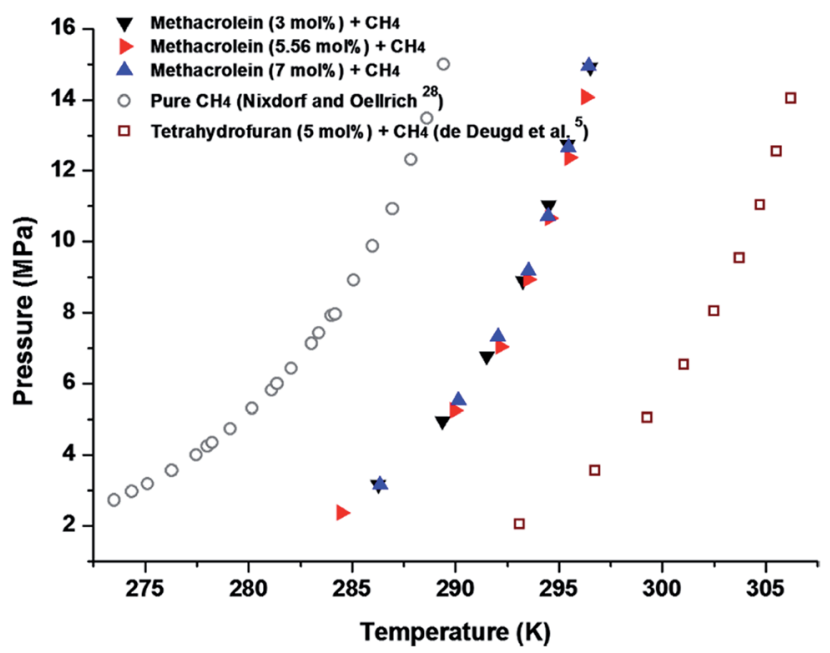

Fig. 6 Phase equilibrium curves of methacrolein $(3,5.56$, and 7 mol\%) $+\mathrm{CH}_{4}$, pure $\mathrm{CH}_{4}{ }^{28}$ and $\operatorname{THF}\left(5\right.$ mol\%) $+\mathrm{CH}_{4}$ hydrates. ${ }^{5}$

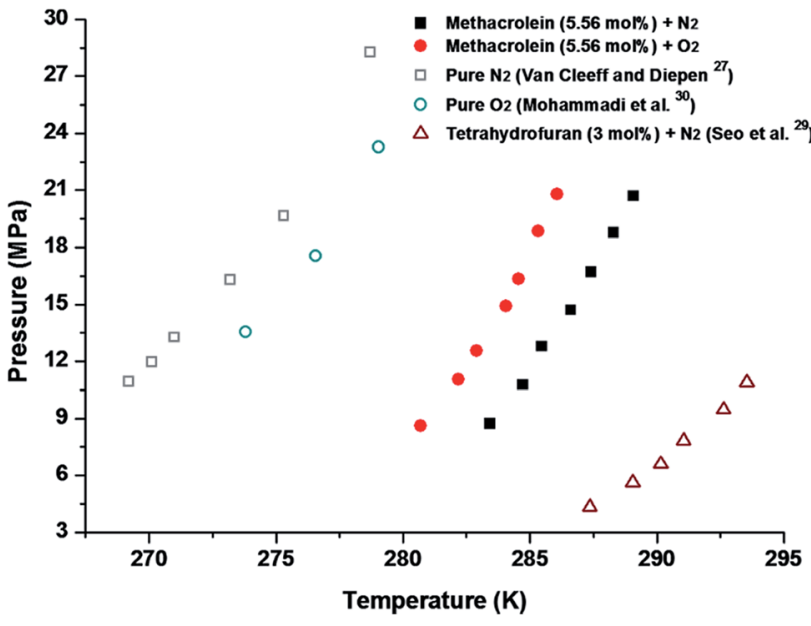

Fig. 7 Phase equilibrium curves of methacrolein $(5.56 \mathrm{~mol} \%)+\mathrm{N}_{2}$, methacrolein $(5.56 \mathrm{~mol} \%)+\mathrm{O}_{2}$, pure $\mathrm{N}_{2},{ }^{27}$ pure $\mathrm{O}_{2},{ }^{30}$ and THF (3 mol\%) $+\mathrm{N}_{2}$ hydrates. ${ }^{29}$

$297 \mathrm{~K}$ for $\mathrm{CH}_{4}$ (Fig. 6), at pressures ranging from 8 to $22 \mathrm{MPa}$ and temperatures ranging from 280 to $290 \mathrm{~K}$ for $\mathrm{N}_{2}$ and $\mathrm{O}_{2}$ (Fig. 7), and at pressures ranging from 0.7 to $3 \mathrm{MPa}$ and temperatures ranging from 274 to $280 \mathrm{~K}$ for $\mathrm{CO}_{2}$ (Fig. 8). The detailed phase equilibrium data for methacrolein with $\mathrm{CH}_{4}, \mathrm{~N}_{2}$, $\mathrm{O}_{2}$, and $\mathrm{CO}_{2}$ are tabulated in Tables 1 and 2 . The phase equilibria of the binary (methacrolein $+\mathrm{CH}_{4}, \mathrm{~N}_{2}$, or $\mathrm{O}_{2}$ ) clathrate hydrates showed that the addition of methacrolein in the hydrate phase increased the hydrate stability with a higher hydrate dissociation temperature when compared to the hydrate stability of pure $\left(\mathrm{CH}_{4}, \mathrm{~N}_{2}\right.$, or $\left.\mathrm{O}_{2}\right)$ clathrate hydrates, but the effect of methacrolein is not stronger than that of tetrahydrofuran..$^{527-30}$ The thermodynamic stability of binary (methacrolein $+\mathrm{CO}_{2}$ ) clathrate hydrate is much higher than that of pure $\mathrm{CO}_{2}$ clathrate hydrate when comparing their hydrate dissociation temperatures below $279 \mathrm{~K}^{.31,32}$ We also monitored the effect of methacrolein concentration on the thermodynamic

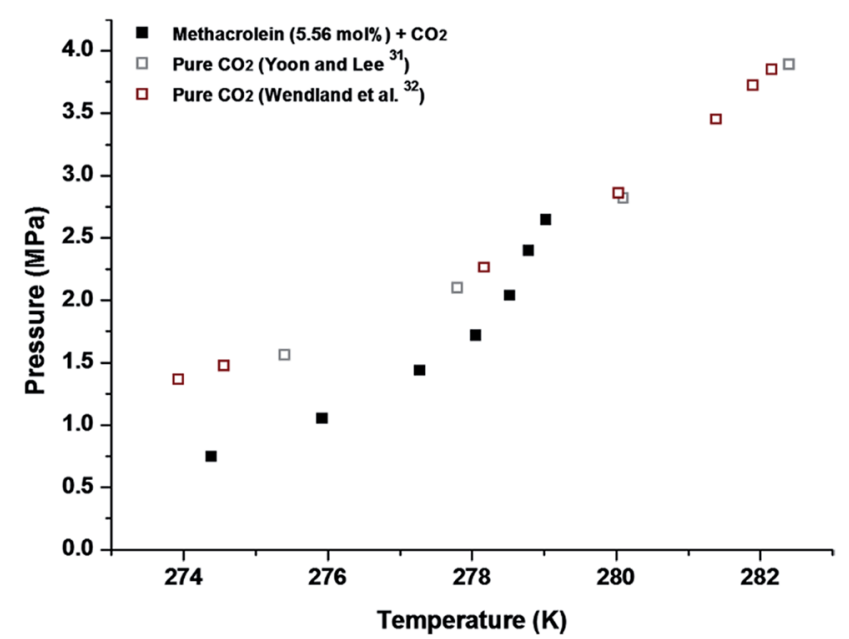

Fig. 8 Phase equilibrium curves of methacrolein (5.56 mol\%) $+\mathrm{CO}_{2}$, and pure $\mathrm{CO}_{2}$ hydrates. ${ }^{31,32}$ 
Table 1 Experimental equilibrium $\left(\mathrm{H}-\mathrm{L}_{\mathrm{w}}-\mathrm{L}_{\text {methacrolein }}-\mathrm{V}\right)$ data of methacrolein $+\mathrm{CH}_{4}$ at various concentrations

Methacrolein $+\mathrm{CH}_{4}$

\begin{tabular}{|c|c|c|c|c|c|}
\hline \multicolumn{2}{|c|}{3 mol\% } & \multicolumn{2}{|c|}{$5.56 \mathrm{~mol} \%$} & \multicolumn{2}{|l|}{$7 \mathrm{~mol} \%$} \\
\hline$T(\mathrm{~K})$ & $P(\mathrm{MPa})$ & $T(\mathrm{~K})$ & $P(\mathrm{MPa})$ & $T(\mathrm{~K})$ & $P(\mathrm{MPa})$ \\
\hline 286.26 & 3.16 & 284.48 & 2.37 & 286.35 & 3.16 \\
\hline 289.38 & 4.95 & 289.96 & 5.26 & 290.14 & 5.53 \\
\hline 291.52 & 6.78 & 292.18 & 7.04 & 292.05 & 7.33 \\
\hline 293.28 & 8.91 & 293.50 & 8.95 & 293.54 & 9.18 \\
\hline 294.50 & 11.02 & 294.57 & 10.66 & 294.48 & 10.71 \\
\hline 295.44 & 12.76 & 295.50 & 12.37 & 295.47 & 12.67 \\
\hline 296.51 & 14.92 & 296.29 & 14.07 & 296.45 & 14.95 \\
\hline
\end{tabular}

Table 2 Experimental equilibrium $\left(\mathrm{H}-\mathrm{L}_{\mathrm{W}}-\mathrm{L}_{\text {methacrolein }}-\mathrm{V}\right)$ data of methacrolein (5.56 mol\%) $+\mathrm{N}_{2}, \mathrm{O}_{2}$, and $\mathrm{CO}_{2}$

Methacrolein $(5.56 \mathrm{~mol} \%)+$ gas

\begin{tabular}{|c|c|c|c|c|c|}
\hline \multicolumn{2}{|l|}{$\mathrm{N}_{2}$} & \multicolumn{2}{|l|}{$\mathrm{O}_{2}$} & \multicolumn{2}{|l|}{$\mathrm{CO}_{2}$} \\
\hline$T(\mathrm{~K})$ & $P(\mathrm{MPa})$ & $T(\mathrm{~K})$ & $P(\mathrm{MPa})$ & $T(\mathrm{~K})$ & $P(\mathrm{MPa})$ \\
\hline 283.42 & 8.73 & 280.69 & 8.64 & 274.38 & 0.75 \\
\hline 284.72 & 10.76 & 282.17 & 11.04 & 275.92 & 1.06 \\
\hline 285.46 & 12.81 & 282.89 & 12.54 & 277.28 & 1.44 \\
\hline 286.61 & 14.71 & 284.07 & 14.92 & 278.06 & 1.72 \\
\hline 287.41 & 16.72 & 284.54 & 16.35 & 278.52 & 2.04 \\
\hline 288.28 & 18.76 & 285.32 & 18.82 & 278.78 & 2.40 \\
\hline 289.08 & 20.70 & 286.06 & 20.79 & 279.03 & 2.65 \\
\hline
\end{tabular}

stability of binary (methacrolein $+\mathrm{CH}_{4}$ ) clathrate hydrates via a concentration change of methacrolein from 3 to $7 \mathrm{~mol} \%$ in the aqueous phase, but there was no significant change in the equilibrium conditions of the binary (methacrolein $+\mathrm{CH}_{4}$ ) clathrate hydrates (Fig. 6). The equilibrium conditions of pure $\mathrm{N}_{2}$ hydrate showed a lower dissociation temperature when compared to those of the pure $\mathrm{O}_{2}$ hydrate with the same pressure conditions (Fig. 6). Interestingly, the equilibrium conditions of binary (methacrolein $+\mathrm{N}_{2}$ ) hydrate showed a higher dissociation temperature when compared to that of the binary (methacrolein $+\mathrm{O}_{2}$ ) hydrate with the same pressure conditions (Fig. 7).

\section{Conclusions}

The crystal structure and guest distributions of binary (methacrolein + gaseous guests) clathrate hydrates were identified using spectroscopic tools, such as powder X-ray diffraction (PXRD) and Raman spectroscopy. The PXRD results showed the formation of structure II hydrates in the presence of methacrolein and gaseous guest molecules. The conformation of methacrolein in the large cages of structure II hydrates was also analyzed via Raman spectroscopy and only one methacrolein conformer, s-trans, was observed in the large cages of structure II hydrates. The relative energy of the s-trans methacrolein is too high for it to fit into the large cages of sII hydrates. High-
Resolution Powder Diffraction (HRPD) and Raman spectroscopy were also used to identify the dissociation of binary (methacrolein $+\mathrm{CH}_{4}$ ) clathrate hydrate, which was almost dissociated at $200 \mathrm{~K}$. Finally, the equilibirum conditions of four phases $\left(\mathrm{H}+\mathrm{L}_{\mathrm{W}}+\mathrm{L}_{\text {methacrolein }}+\mathrm{V}\right)$ of binary (methacrolein + gaseous guests) clathrate hydrates were also tested using a conventional isochoric method. The phase equilibria of binary (methacrolein $+\mathrm{CH}_{4}, \mathrm{~N}_{2}$, or $\mathrm{O}_{2}$ ) clathrate hydrates showed that the addition of methacrolein in the hydrate phase increased the hydrate stability with a higher hydrate dissociation temperature when compared with those of pure $\left(\mathrm{CH}_{4}, \mathrm{~N}_{2}\right.$, or $\left.\mathrm{O}_{2}\right)$ clathrate hydrates. The thermodynamic stability of the binary (methacrolein $+\mathrm{CO}_{2}$ ) clathrate hydrate exhibits a higher hydrate dissociation temperature compared to that of pure $\mathrm{CO}_{2}$ clathrate hydrate below $279 \mathrm{~K}$.

\section{Acknowledgements}

This research was supported by the Nuclear R\&D Program through a grant from the National Research Foundation (NRF) of Korea, funded by the Ministry of Science, ICT and Future Planning (MSIP) (NRF-2015M2B2A4029581).

\section{References}

1 E. D. Sloan, Nature, 2003, 426, 353-359.

2 E. D. Sloan and C. A. Koh, Clathrate Hydrates of Natural Gases, CRC press (Taylor and Francis Group), 3rd edn, 2008.

3 H. Kang, Y. H. Ahn, D. Y. Koh, S. Baek, J. W. Lee and H. Lee, Ind. Eng. Chem. Res., 2016, 55, 6079-6084.

4 H. P. Veluswamy, A. J. H. Wong, P. Babu, R. Kumar, S. Kulprathipanja, P. Rangsunvigit and P. Linga, Chem. Eng. J., 2016, 290, 161-173.

5 R. M. de Deugd, M. D. Jager and J. D. Arons, AIChE J., 2001, 47, 693-704.

6 R. Ohmura, S. Matsuda, S. Takeya, T. Ebinuma and H. Narita, Int. J. Thermophys., 2005, 26, 1515-1523.

7 D. Lim, S. Park, H. Ro, K. Shin and H. Lee, J. Phys. Chem. C, 2015, 119, 10218-10226.

8 B. J. Wu, D. B. Robinson and H. J. Ng, J. Chem. Thermodyn., 1976, 8, 461-469.

9 S. W. Davidson, S. K. Garg, S. R. Gough, R. E. Hawkins and J. A. Ripmeester, Can. J. Chem., 1977, 55, 3641-3650.

10 J. A. Ripmeester and C. I. Ratcliffe, J. Phys. Chem., 1990, 94, 8773-8776.

11 K. Shin, Y. Park, J. H. Hong and H. Lee, Korean J. Chem. Eng., 2007, 24, 843-846.

12 Y. Park, M. Cha, W. Shin, H. Lee and J. A. Ripmeester, J. Phys. Chem. B, 2008, 112, 8443-8446.

13 M. Cha, K. Shin and H. Lee, J. Phys. Chem. B, 2009, 113, 10562-10565.

14 B. Sung, K. Shin, M. Cha, S. Choi, J. Lee, Y. Seo and H. Lee, J. Chem. Eng. Data, 2010, 55, 5906-5909.

15 J. W. Lee, H. L. Lu, I. L. Moudrakovski, C. I. Ratcliffe, R. Ohmura, S. Alavi and J. A. Ripmeester, J. Phys. Chem. A, 2011, 115, 1650-1657. 
16 M. Cha, M. Kwon, Y. Youn, K. Shin and H. Lee, J. Chem. Eng. Data, 2012, 57, 1128-1133.

17 M. J. Cha, H. Lee and J. W. Lee, J. Phys. Chem. C, 2013, 117, 23515-23521.

18 M. J. Cha, S. Baek, H. Lee and J. W. Lee, RSC Adv., 2014, 4, 26176-26180.

19 Y. Youn, M. Cha and H. Lee, ChemPhysChem, 2015, 16, 28762881.

20 Y. H. Ahn, H. K. Lim, H. Kang, H. Kim, M. Cha, K. Shin and H. Lee, J. Phys. Chem. C, 2016, 120, 17190-17195.

21 Y. H. Ahn, H. Kang, D. Y. Koh, Y. Park and H. Lee, Fluid Phase Equilib., 2016, 413, 65-70.

22 G. W. T. M. J. Frisch, H. B. Schlegel, G. E. Scuseria, M. A. Robb, J. R. Cheeseman, J. A. Mongomery, T. Vreven, K. N. Kudin, J. C. Brunt, J. M. Millam, S. S. Iyengar, J. Tomasi, V. Barone, B. Mennucci, M. Cossi, G. Scalmani, N. Rega, G. A. Petersson, H. Nakatsuji, M. Hada, M. Ehara, K. Toyota, R. Fukuda, J. Hasegawa, M. Ishida, T. Nakajima, Y. Honda, O. Kitao, H. Nakai, M. Klene, X. Li, J. E. Kmox, H. P. Hratchian, J. B. Cross, V. Bakken, C. Adamo, J. Jaramillo, R. Gomperts, R. E. Stratmann, O. Yazyev, A. J. Austin, R. Cammi, C. Pomelli, J. W. Ochterski, P. Y. Ayala, K. Morokuma, G. A. Voth, P. Salvador, J. J. Dannenberg, V. G. Zakrzewski, S. Dapprich, A. D. Daniels, M. C. Strain, O. Farkas, D. K. Malick, A. D. Rabuck, K. Raghavachari, J. B. Foresman, J. V. Ortiz, Q. Cui, A. G. Baboul, S. Clifford, J. Cioslowski,
B. B. Stefanow, G. Liu, A. Liashenko, P. Piskorz, I. Komaromi, R. L. Martin, D. J. Fox, T. Keith, M. A. AlLaham, C. Y. Peng, A. Nanayakkara, M. Challacombe, P. M. W. Gill, B. Johnson, W. Chen, M. W. Wong, C. Gonzalez and J. A. People, Gaussian Inc., Wallingford, CT, 2004.

23 J. R. Durig, J. Qiu, B. Dehoff and T. S. Little, Spectrochim. Acta, Part A, 1986, 42, 89-103.

24 C. Barba, D. Carmona, J. I. Garcia, M. P. Lamata, J. A. Mayoral, L. Salvatella and F. Viguri, J. Org. Chem., 2006, 71, 9831-9840.

25 O. Zakharenko, R. A. Motiyenko, J. R. A. Moreno, A. Jabri, I. Kleiner and T. R. Huet, J. Chem. Phys., 2016, 144, 024303.

26 L. T. Chen, H. L. Lu and J. A. Ripmeester, Chem. Eng. Sci., 2015, 138, 706-711.

27 A. Van Cleeff and G. A. M. Diepen, Recl. Trav. Chim. Pays-Bas, 1960, 79, 582-586.

28 J. Nixdorf and L. R. Oellrich, Fluid Phase Equilib., 1997, 139, 325-333.

29 Y. T. Seo, S. P. Kang and H. Lee, Fluid Phase Equilib., 2001, 189, 99-110.

30 A. H. Mohammadi, B. Tohidi and R. W. Burgass, J. Chem. Eng. Data, 2003, 48, 612-616.

31 J. H. Yoon and H. Lee, AIChE J., 1997, 43, 1884-1893.

32 M. Wendland, H. Hasse and G. Maurer, J. Chem. Eng. Data, 1999, 44, 901-906. 